\title{
Computação e linguagem: uma nova abordagem para aproximar meninas em idade escolar das áreas STEM
}

\author{
Ana Paula Lüdtke Ferreira ${ }^{1}$, Márcia Maria Lucchese ${ }^{1}$ \\ ${ }^{1}$ Universidade Federal do Pampa (UNIPAMPA) - Campus Bagé \\ \{anaferreira, marcialucchese\}@unipampa.edu.br
}

\begin{abstract}
Aligning with the UN Agenda 2030, organized civil society has made efforts to reduce gender inequalities in STEM courses and careers. This work presents a linguistic approach to the introduction to Computing in Basic Education, by taking advantage of the gender stereotype that women are more interested in Human and Social Sciences courses. The preliminary results show that even students with no previous interest in joining Computing in Higher Education were interested in carrying out the proposed activities.
\end{abstract}

Resumo. Alinhada com a Agenda 2030 da ONU, a sociedade civil organizada tem envidado esforços para a diminuição das desigualdades de gênero nos cursos e carreiras das áreas STEM. Este trabalho apresenta uma abordagem linguística para introdução à Computação no Ensino Básico tirando partido do estereótipo de gênero de que mulheres são mais interessadas em cursos das Ciências Humanas e Sociais. Os resultados preliminares mostram que mesmo as estudantes sem interesse prévio em ingressar na Computação no Ensino Superior mostraram-se interessadas na execução das atividades propostas.

\section{Introdução}

A Agenda 2030 da ONU para o Desenvolvimento Sustentável consiste em um conjunto de objetivos, destacando-se a igualdade de gênero e a redução das desigualdades. O Plano Nacional de Educação 2014-2024 (Lei n 13.005/2014) estabelece a "superação das desigualdades educacionais, com ênfase na promoção da cidadania e na erradicação de todas as formas de discriminação". Essas metas estão conectadas à diminuição das desigualdades no número de mulheres nos cursos da área de Computação e nas profissões associadas. Os esforços governamentais e de organizações da sociedade civil em relação à diminuição das desigualdades de gênero não se mostraram suficientes. Na educação superior, as mulheres somam 35\% dos alunos matriculados nos cursos das áreas STEM (Science, Technology, Engineering, and Mathematics); no mercado, elas têm 20\% dos empregos nas áreas da tecnologia; na academia, somente $28 \%$ dos pesquisadores são mulheres [UNESCO 2018]. Um recente estudo [O'Dea et al. 2018] mostra que o desempenho médio das mulheres na educação superior é maior do que o desempenho médio dos estudantes do sexo masculino, inclusive nos cursos das áreas STEM, sendo a variância inferior à dos homens; ou seja, o desempenho das mulheres é mais consistente e regular. O Censo da Educação Superior brasileira aponta que o índice de evasão das mulheres nos cursos STEM é menor que o dos homens. O cumprimento das diretrizes e metas nacionais e mundiais de desenvolvimento da educação e da tecnologia depende instrinsicamente do aumento do ingresso das mulheres nessas áreas. 
A falta de interesse das meninas pelas áreas STEM é resultado dos processos de socialização e de aprendizagem, e não de atributos intelectuais ou genéticos [UNESCO 2018]. A intervenção no ambiente escolar, onde ocorre o contato com o conhecimento e onde as estratégias de socialização são desenvolvidas, é chave para a oferta de oportunidades iguais. O interesse das meninas pela educação superior é usualmente orientada para profissões mais "femininas" [Romero 1994], [Moreno 1999], [Silva 2017], [Brito 2016], que têm em comum a leitura de textos, em detrimento das "áreas duras", caracterizadas pelo uso da linguagem matemática. A crença de que meninas são mais propensas a esses campos de estudo/profissões acaba se tornando uma profecia autorealizada e elas, efetivamente, formam o maior percentual de estudantes nessas áreas [Sampaio et al. 2019].

O objetivo deste trabalho é aproveitar a orientação dada às meninas para cursos superiores com forte embasamento linguístico para promover uma maior aproximação delas com a área de Computação. A ideia é apresentar os profissionais da Computação como "pessoas que falam com máquinas" e inserir os conteúdos a partir dos conhecimentos usualmente desenvolvidos nas disciplinas de Teoria da Computação e de Teoria dos Códigos. O projeto está em andamento e vem sendo adaptado conforme novas experiências vão acontecendo, pois tem uma característica bastante diversa da introdução dos conceitos de computação pela via da programação.

O restante deste trabalho está organização como se segue: a Seção 2 apresenta o contexto, os princípios e o trabalho realizado; a Seção 3 discute resultados preliminares; e a Seção 4 faz o fechamento com considerações sobre o trabalho desenvolvido.

\section{Oficinas de computação e linguagem}

O trabalho foi conduzido em Bagé (RS), distante $380 \mathrm{~km}$ de Porto Alegre e $60 \mathrm{~km}$ do Uruguai. O IDHM de Bagé é 0,740 (IBGE, 2010), correspondendo à faixa de desenvolvimento humano alto. Contudo, o índice de Educação na cidade é 0,647, estando no $764^{\circ}$ lugar entre as cidades do país. A atividade foi realizada em duas escolas, com 62 participantes ( 24 meninos e 38 meninas). Como as atividades foram feitas no espaço escolar durante os horários de aula, não foi possível excluir os meninos. De toda forma, a discussão sobre gênero nas áreas STEM foi apresentada, deixando claro que todos seriam capazes de fazer as atividades e seguir as carreiras e profissões relacionadas à Computação.

O que faz um profissional de Computação? Essa pergunta dá início ao processo e a resposta dada é "nós falamos com máquinas". A segunda pergunta a ser respondida é "Como nos comunicamos?". O objetivo era revelar os padrões existentes nos processos de comunicação. $\mathrm{O}$ apoio visual continha imagens com mensagens escritas em diferentes tipos de línguas e linguagens humanas. A Fig. 1 mostra algumas das imagens usadas para a introdução da oficina.

A partir da proposição das questões "por que conseguimos entender algumas mensagens e não outras?" e "o que constitui uma forma de comunicação?", as noções de "símbolo", "alfabeto", "palavra" e "texto" surgem com naturalidade. Mesmo sem as definições formais usadas no contexto da Computação, o significado conhecido estabelece a ancoragem do conhecimento nos estudos já realizados no âmbito da Língua Portuguesa, necessária para um aprendizado consistente [Cardoso and Queiroz 2019].

O primeiro desafio posto foi a comunicação de datas de nascimento, usando 


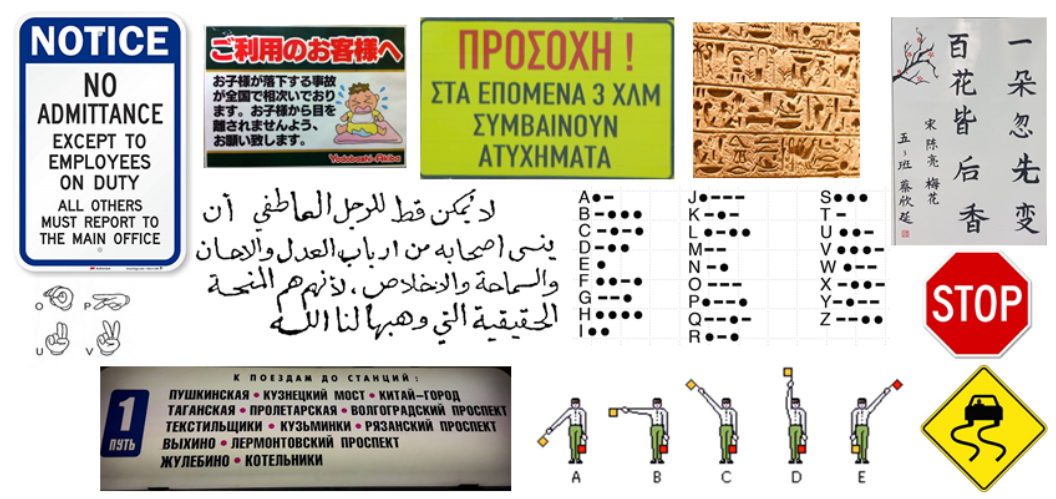

Figura 1. Imagens sobre diferentes tipos de linguagens

cartões com três símbolos distintos (um círculo, um quadrado e um losango). O uso de símbolos sem relação com números ou letras foi proposital, evitando estabelecer conexões com outros alfabetos conhecidos. A tarefa foi proposta em fases: (i) construir a representação das datas de nascimento com os símbolos do alfabeto; (ii) preparar uma tabela ou um esquema para tradução; (iii) passar uma data e a tabela de tradução para o grupo ao lado. (iv) receber uma data e uma tabela de tradução de outro grupo; (v) traduzir a data recebida; (vi) verificar os resultados.

Findas as traduções de datas o alfabeto binário é formalmente apresentado. O processo de ancoragem pode ser agora realizado, dada a experiência com o alfabeto ternário usado na oficina. A tabela ASCII é introduzida como o esquema de tradução entre a nossa linguagem e a linguagem dos computadores. A aritmética binária foi evitada propositadamente: a ligação da Computação com a Matemática, uma vez estabelecida, pode fazer com que a curiosidade diminua e acabe tornando o trabalho contraproducente.

A segunda oficina teve como tema "Como transmitimos informação?". A ideia não era explicar mecanismos técnicos, mas trabalhar a ideia de canal de comunicação passível de erros de transmissão, motivada por questionamentos do tipo "como teclamos uma mensagem e ela aparece no aparelho de outra pessoa?". As discussões envolveram a identificação de canais de comunicação humana típicos: voz, gestos, telefone, vídeo, mensagens de texto, e-mails, etc. Mensagens de texto e exemplos de falas com erros foram apresentados, questionando sobre o porquê de entendermos mensagens com erros. Questões sobre a semântica das mensagens, o entendimento do contexto e a similaridade com palavras que conhecemos foram levantadas pelos participantes. Mas como seria no caso das máquinas, com transmissão somente de 0 e 1 , sem contexto, sem semântica associada, sem possibilidade de comparação? Como é possível alterar a informação transmitida para que seja possível detectar um erro de transmissão?

A atividade a seguir, para exemplificar o processo de identificação e correção de erros de transmissão de dados, foi adaptada do livro Computer Science Unplugged [Bell et al. 2015]. O propósito foi ensinar como a adição de redundância na informação pode ser usada para identificar e corrigir erros de transmissão, na forma de um desafiador "truque de mágica". O experimento consistiu em colocar cartas do alfabeto ternário, viradas para cima ou para baixo, dispostas em uma superfície, formando um quadrado ou um retângulo. O "truque", no caso, é dispor os elementos de forma que todas as linhas e colunas tenham um número par de elementos brancos. Os participantes são instados, após 
o afastamento do condutor do processo, a alterar um único símbolo da matriz, virando a carta para o seu lado oposto. Naturalmente, a carta virada é aquela que está na intersecção entre a linha e a coluna com paridade ímpar. Não havia expectativa de que a "mágica" por trás da atividade fosse descoberta. Mas a curiosidade frente a um acontecimento aparentemente inexplicável (afinal, a condutora da atividade sempre acertava qual era a carta virada) manteve a atenção de todos. Após algumas repetições, o "truque" é explicado aos alunos.

\section{Resultados parciais}

A abordagem baseada em Teoria dos Códigos e em Linguagens Formais para introdução à Computação é nova, sem registro na literatura pesquisada e ainda está em fase experimental. A motivação dos alunos para essa abordagem foi constatada in loco, pelo engajamento dos participantes e diversidade de soluções encontradas. A criatividade dos estudantes do Ensino Básico é pouco explorada em aulas conteudistas e dissociadas de métodos voltados à solução de problemas, característica intrínseca ao fazer dos profissionais da área de Computação. Nas soluções apresentadas, houve quem trabalhasse com números, usando os símbolos para representar algarismos romanos - causando um processo de tradução duplo datas $\rightarrow$ números romanos $\rightarrow$ números arábicos, sendo o único grupo que não foi entendido pelos demais; quem usasse espaço entre os símbolos para separar os números componentes das datas, sem entender que o espaço também era um símbolo, tendo sido alertados para isso no processo; grupos que usaram códigos de comprimento fixo e com isso resolveram o problema rapidamente e sem ambiguidade; grupos que usaram códigos de comprimento variável sem se dar conta da questão dos prefixos; grupos que mudaram a orientação das cartas com losangos para aumentar o número de símbolos; assim como várias outras abordagens interessantes. Um resultado importante, na análise feita das oficinas, foi de como nenhum dos grupos se preocupou com representações compactas no sentido de usar o menor número de símbolos possível, ainda que todas as soluções fossem distintas em forma e concepção.

O processo de interesse, que é o ensino de computação - ou, pelo menos, a apresentação de alguns de seus elementos, precisa ser mantido e aprofundado. O maior desafio existente é a migração do lúdico para uma abordagem sistemática e rigorosa, sem perder as características propostas, de ensinar Matemática sem chamá-la pelo nome. $\mathrm{O}$ problema de pesquisa inicial: "O entendimento da Computação como linguagem favoreceria o entendimento da Matemática como linguagem, de forma que os pré-conceitos desenvolvidos ao longo da vida escolar possam ser superados?" também não pode ser investigado enquanto a migração do modelo lúdico para o modelo formal não foi construído.

\section{Considerações finais}

Os estereótipos de gênero são construídos desde a infância e a escola não é imune a eles. Meninas são socializadas para atitudes submissas e recompensadas quando mostram delicadeza e pertencimento ao grupo. Meninos são estimulados a apresentar atitudes assertivas e a se sobressaírem dos demais. Na escola, proposital ou inadvertidamente, elas são orientadas a seguir carreiras associadas às Ciências Humanas e Sociais. Não por acaso, são maioria nessas áreas. 
A sociedade organizada vem se empenhando em diminuir as desigualdades de gênero nas áreas STEM por meio do incentivo ao ingresso de mulheres em seus cursos e carreiras. Este trabalho encontra-se no escopo desse esforço, com atividades propostas em cinco escolas públicas. As oficinas introduzem a Computação com uma abordagem linguística - em oposição à introdução do assunto por meio de algoritmos. Nessa abordagem, o profissional da área é apresentado como uma pessoa que "fala com máquinas". O paradigma subjacente é a computação desplugada, que prevê o ensino de computação que busca ensinar computação sem o uso de computadores, também devido às condições financeiras limitadas das escolas estaduais do RS e municipais de Bagé.

Os resultados inicias são promissores, pois mesmo os alunos que não pretendem ingressar na área mostraram-se interessados e participativos. O desafio existente é migrar do modelo lúdico inicial para um modelo formal que possa ser introduzido sem perda da ideia inicial. Esse desafio é relevante, visto que a formalização dos conceitos em linguagem matemática poderá levar a um melhor entendimento e a uma menor aversão da matéria pelos estudantes.

Agradecimentos - Ao CNPq, pelos recursos recebidos por meio da Chamada Pública CNPq/MCTIC n ${ }^{\circ}$ 31/2018, no âmbito do projeto Gurias do Pampa nas Exatas.

\section{Referências}

Bell, T., Witten, I. H., and Fellows, M. (2015). Computer Science Unplugged. Google Inc., 3 edition.

Brito, A. F. (2016). Gênero na escola: educação de meninos X educação de meninas. CCCSS Contribuciones a las Ciencias Sociales.

Cardoso, M. A. and Queiroz, S. L. (2019). As contribuições da neurociência para a educação e a formação de professores: um diálogo necessário. Cadernos da Pedagogia, 12(24):30-47.

Moreno, M. (1999). Como se ensina a ser menina: o sexismo na escola. Editora da Unicamp, Campinas.

O’Dea, R. E., Lagisz, M., Jennions, M. D., and Nakagawa, S. (2018). Gender differences in individual variation in academic grades fail to fit expected patterns for STEM. Nature Communications, 9(3777).

Romero, E. (1994). A educação física a serviço da ideologia sexista. Revista Brasileira de Ciências do Esporte, 15(3):226-234.

Sampaio, C. E. M. et al. (2019). Resumo Técnico do Censo da Educação Superior 2017. DEED/INEP, Brasília, DF.

Silva, J. A. (2017). Aprendizagens relacionadas aos estereótipos de gênero na educação infantil. Revista Educação, 12(1):60-73.

UNESCO (2018). Decifrar o código: educação de meninas e mulheres em ciências, tecnologia, engenharia e matemática (STEM). Organização das Nações Unidas para a Educação, a Ciência e a Cultura (UNESCO), Brasília, DF. 